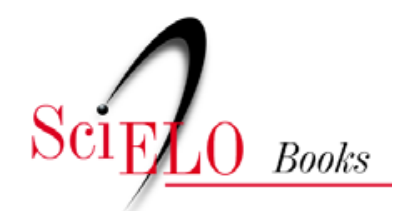

\title{
Capítulo 11 - Ampliando o olhar sobre o programa de formação continuada de professores das Salas de Recursos Multifuncionais da cidade do Rio de Janeiro
}

\author{
Patrícia Fernandes Ferreira \\ Leila Regina d'Oliveira de Paula Nunes \\ Carolina Rizzotto Schirmer
}

\section{SciELO Books / SciELO Livros / SciELO Libros}

FERREIRA, P. F., NUNES, L. R. O. P., and SCHIRMER, C. R. Ampliando o olhar sobre o programa de formação continuada de professores das Salas de Recursos Multifuncionais da cidade do Rio de Janeiro. In: NUNES, L. R. O. P., and SCHIRMER, C. R., orgs. Salas abertas: formação de professores e práticas pedagógicas em comunicação alternativa e ampliada nas salas de recurso multifuncionais [online]. Rio de Janeiro: EDUERJ, 2017, pp. 243-258. ISBN: 978-85-7511-452-0. Available from: doi: 10.7476/9788575114520.013. Also available in ePUB from: http://books.scielo.org/id/xns62/epub/nunes-9788575114520.epub.

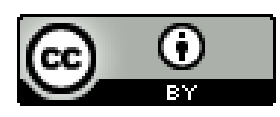

All the contents of this work, except where otherwise noted, is licensed under a Creative Commons Attribution 4.0 International license.

Todo o conteúdo deste trabalho, exceto quando houver ressalva, é publicado sob a licença Creative Commons Atribição 4.0.

Todo el contenido de esta obra, excepto donde se indique lo contrario, está bajo licencia de la licencia $\underline{\text { Creative Commons }}$ $\underline{\text { Reconocimento 4.0. }}$ 


\title{
Capítulo 11 - Ampliando o olhar sobre o programa de formação continuada de professores das Salas de Recursos Multifuncionais da cidade do Rio de Janeiro
}

\author{
Patricia Fernandes Ferreira ${ }^{1}$ \\ Leila Regina d'Oliveira de Paula Nunes ${ }^{2}$ \\ Carolina Rizzotto Schirmer ${ }^{3}$
}

O Programa de Implantação de Salas de Recursos Multifuncionais (SRMs), instituído pelo Ministério da Educação, por intermédio da Secretaria de Educação Continuada, Alfabetização, Diversidade e Inclusão - SECADI, vem garantindo o atendimento educacional especializado, de forma complementar ou suplementar ${ }^{4}$ (atualmente, Transtornos do Espectro do Autismo), aos educandos com deficiência, transtornos globais do desenvolvimento, e altas habilidades matriculados no ensino regular. $\mathrm{O}$ professor do AEE deve considerar as habilidades e as necessidades educacionais específicas dos estudantes público-alvo da Educação Especial para oferecer um atendi-

1 Mestranda em Educação pelo Programa de Pós-Graduação em Educação da UERJ. Secretaria Municipal de Educação do Rio de Janeiro. E-mail:pferreira@rioeduca.net.

2 Professora titular da Faculdade de Educação e do Programa de Pós-Graduação em Educação da UERJ. E-mail: leilareginanunes@terra.com.br.

3 Professora adjunta da Faculdade de Educação da UERJ. E-mail: ead.carolina@gmail. com.

4 Atualmente Transtornos de Espectro do Autismo 
mento que elimine os obstáculos que impedem o desenvolvimento da sua aprendizagem e a participação na sociedade.

A ampliação da oferta do Atendimento Educacional Especializado na rede municipal de ensino do Rio de Janeiro pleiteia uma formação continuada que permita ao professor refletir sobre a sua ação, implementar melhores práticas pedagógicas e desenvolver um olhar sobre os processos educacionais que se assente no princípio de que toda criança pode aprender. Diante do exposto, o Instituto Helena Antipoff (IHA), por intermédio da Oficina Vivencial (OV) e da UERJ, vem desenvolvendo, desde o ano de 2013, um projeto para a implantação das Salas de Recursos Multifuncionais de Referência. Programa este que proporcionou a construção de espaços de multiplicação da Tecnologia Assistiva nas onze Coordenadorias Regionais de Educação do Rio de Janeiro.

As atividades desenvolvidas tiveram a finalidade de implementar e avaliar um programa de formação continuada de professores da rede pública de ensino municipal para atuação nas SRMs de Referência, que funcionarão como agentes multiplicadores das ações formativas da OV. Durante os quatro anos de realização do projeto, os docentes que atuam em SRMs foram ensinados a planejar, implementar e avaliar recursos e serviços de Tecnologia Assistiva (TA) e Comunicação Alternativa e Ampliada (CAA) para atender alunos do ensino fundamental que apresentem severos comprometimentos em sua comunicação oral.

No final de 2016, uma entrevista semiestruturada foi realizada com cada professor que participou do projeto. Esse procedimento de coleta de informações tem sido muito utilizado na pesquisa em educação, pois permite a descrição do fenômeno estudado por meio de perguntas principais que podem ser complementadas por outras questôes pertinentes ao assunto da investigação. As entrevistas foram realizadas pelas professoras da $\mathrm{OV}$ e pelas mestrandas da UERJ, Patrícia Ferreira e Stefhanny Silva.

As entrevistas tiveram como foco principal a compreensão do trabalho do professor que atende nas SRMs de Referência e sua relação com os professores das classes comuns, além da avaliação de todo o curso de formação ofertado ao grupo de docentes participantes desde 2013 pela OV, juntamente com professoras da UERJ. As entrevistas tiveram duração mínima de 30 minutos e máxima de 90 minutos, foram realizadas nas escolas em que as professoras são regentes e gravadas em áudio ou vídeo. 
Foi realizada uma análise de conteúdo preliminar das entrevistas, que mostraram, antes de tudo, que os professores e diretores da unidade escolar possuem demasiadas e equivocadas expectativas com relação ao trabalho na SRM, pois desconhecem as reais funções desse serviço e acreditam que o Atendimento Educacional Especializado deve assumir, solitariamente, o processo de desenvolvimento, ensino e aprendizagem dos alunos público-alvo da educação especial. Podemos confirmar o que foi declarado por meio das falas das professoras citadas abaixo e cujos nomes são fictícios:

Mariana: Pois é, as atribuiçōes da sala de recursos eu preciso sempre explicar, porque, às vezes, eles criam expectativas que vão além das atribuiçôes da sala de recursos. E o problema não é exatamente este, mas é que isto pode acabar prejudicando a inclusão de fato, porque senão o aluno passa a ser só da sala de recursos. [...] E aí assim, tem sempre que explicar o público-alvo, tem sempre que estar explicando. Ainda mais quando muda o professor e às vezes chega um professor que não conhece nada de autismo.

Como vimos, as incumbências dos professores que atendem nas Salas de Recursos Multifuncionais, assim como o seu público-alvo, ainda não estão claros para os docentes da turma regular. Esse desconhecimento acarreta um estado de apreensão e medo. Até certo ponto, essa reação é natural, sendo útil para o professor adaptar-se e reagir perante essa situação de grande expectativa. Contudo, quando ela atinge um nível que interfere no fazer pedagógico do docente, constrói uma barreira na construção de uma escola de qualidade para todos. O professor de SRM precisa estar, a todo momento, oferecendo assessoramento para esclarecer todas as peculiaridades que envolvem o seu ofício. Esse fato atrapalha o desenvolvimento das atividades com alunos, pois não há uma unidade no trabalho. Ele fica um tanto isolado dentro de um universo muito maior, que é a escola, como mostra o seguinte relato:

Karla: A ansiedade é total, por isso que eu faço questão de a primeira vez que eu vou conhecer, já vou assim cheia de documentos, com propostas, levo a maneira como trabalho, justamente para tentar minimizar isso e mostrar que a gente está junto, que fazemos parte de uma equipe e que vamos tentar com o objetivo de conseguir. 
O gestor, por sua vez, também não compreende as obrigações do AEE junto à sua comunidade escolar. De acordo com as informações coletadas nas entrevistas, esse profissional é visto como salvador, tranquilizador de alunos e professores, avaliador de alunos, um mágico que chega à escola e resolve todos os problemas, um fiscalizador do seu trabalho. Enquanto esse papel não estiver bem claro, ainda encontraremos instituições escolares com discurso inclusivo, mas com atitudes excludentes, pois estão sendo dirigidas por profissionais que não se apropriaram de todos os aspectos que envolvem o fazer pedagógico.

$\mathrm{O}$ desconhecimento e a falta de confiança que professores regulares e gestores mostram com relação ao papel do professor das salas de recursos multifuncionais, assim como o isolamento e o sentimento de desvalorização que esse professor vivencia, foram registrados igualmente pelo conjunto de estudos desenvolvidos por 76 pesquisadores oriundos de 21 universidades localizadas em 38 municípios brasileiros, com a participação de 596 professores das Salas de Recursos Multifuncionais e coordenados pela professora Enicéia Mendes, no Observatório Nacional de Educação Especial, iniciado em 2010 e finalizado em 2015 (Mendes et al., 2015a; Mendes et al., 2015b).

Carmen': Olha, tem diretor que, quando me recebe, acha que eu tenho que resolver. Tem diretor que acha que aluno é meu e não da escola. Tem diretor que acha que eu sou alguém do IHA e que eu tenho que resolver esse problema. Tem gente que fala assim 'Você como é lá do IHA, pode me ajudar'. Tem diretor que acha que eu sou avaliadora para avaliar o fulaninho que não é da sala de recursos.

O diretor da unidade escolar é personagem principal nesse processo de implantação de uma cultura educacional inclusiva e precisa estar preparado para articular conhecimentos, pessoas e processos. Entre as escolas participantes da pesquisa, também encontramos líderes que garantem a abertura de novos espaços de diálogo e parceria destinados à transformação do cotidiano escolar. Sua posição de autoridade, liderança e, principalmente, seu papel articulador dentro da escola foram fundamentais para a construção de um espaço de qualidade para todos.

5 Nome fictício. 
Eliane $^{6}$ : Eles dão total apoio. A direção tem essa visão de inclusão tanto que eu lhe falei que esse projeto é um ganho também de toda a escola que visa, que tem esse foco no aluno especial. $\mathrm{E}$ a direção tem dado todo apoio.

Anete: Eu acho que também tenho um trunfo muito grande que é a direção. Isso eu acho que é fundamental no trabalho. Eu mostrei o meu valor, elas acreditam nesse valor e elas compram a briga. Então, isso é um diferencial tanto aqui quanto na outra escola.

A inclusão educacional constitui um processo complexo e inovador que exige mudanças de atitude e uma reflexão permanente a respeito das lógicas que regem a reestruturação e o ordenamento das instituições escolares. O gestor, por meio de suas atitudes, pode facilitar ou dificultar o desenvolvimento de uma cultura na qual o diálogo e a parceria devam ser o carro chefe para a implantação de processos educativos e de relações que favoreçam ações e responsabilidades compartilhadas. Nos últimos anos, essa ideia de colaboração vem sendo defendida com muita propriedade por vários estudiosos da área da educação em geral e, mais especificamente, na prática do professor do atendimento educacional especializado. Este precisa realizar um trabalho articulado com o regente da turma comum para que se possa garantir o acesso do aluno com deficiência ao conhecimento, ao espaço físico, às interações e à comunicação.

De acordo com a análise do conteúdo das entrevistas, tem sido um grande desafio estabelecer uma relação de troca e colaboração com a maioria dos professores das turmas regulares, tencionando obter maiores informações sobre seus desempenhos e gerar maior probabilidade do que o trabalho desenvolvido nas Salas de Recursos Multifuncionais reflita nas classes comuns. Vários obstáculos têm se colocado no caminho dessa via de mão dupla: a ausência de uma Sala de Recursos Multifuncionais em cada escola; as inúmeras atribuições do professor do AEE; a resistência de alguns professores em aceitar o aluno com deficiência em sua turma; a rejeição das orientações de trabalho oferecidas pelo AEE; a falta de contato com todos os professores

6 Nome fictício 
que atuam no segundo segmento ${ }^{7}$; a falta de conhecimento do professor da turma regular e do diretor sobre a deficiência apresentada pelo aluno; a falta de espaço nas reuniões pedagógicas; a falta de relações interpessoais com os demais professores; a rotatividade de educadores e diretores; e o trabalho desarticulado com a proposta de uma educação inclusiva.

$\mathrm{O}$ professor especialista, aquele que atende às turmas de segundo segmento, constantemente questiona os regentes que atuam no Atendimento Educacional Especializado com relação às suas capacidades acadêmicas para realizar adaptações de aprendizagem para os alunos público-alvo da educação especial das disciplinas das quais não possuem formação. Ele sente-se afrontado e invadido quando alguém que, supostamente, tem um conhecimento inferior ao dele com relação àquela matéria tenta lhe dizer como trabalhar com determinado aluno. $\mathrm{O}$ educador do AEE aproveita todos esses momentos para estabelecer um diálogo colaborativo com esse docente. Investiga seus interesses em relação ao aluno com necessidades educacionais especiais para, a partir deles, tentar estabelecer uma comunicação, buscando a quebra das barreiras que impedem uma relação de parceria entre eles, mas nem sempre obtém sucesso. Alguns regentes, definitivamente, demonstram não desejar estabelecer essa parceria com o AEE.

Anete: Já fui questionada de qual é a minha formação várias vezes, principalmente pelo professor de Matemática. 'Ah, mas qual é a sua formação para você ensinar Matemática?' Eu falei que a minha formação era de Geografia, como PI, mas eu tinha estudado até o $9^{\circ}$ ano. Então, eu poderia não saber Matemática no mesmo nível que ele, mas no mesmo nível que o meu aluno precisava eu sabia. E que quando eu não soubesse eu pediria ajuda a ele.

Luana: Tem alguns que realmente são porta fechada, eles não querem. Porque o que eles querem é um professor de reforço. Não tem um professor de reforço, então a sua parceira não me interessa. E aí eu vou tentando abrir essa porta, eu vou forçando um pouquinho, mas sempre com muita leveza, com afetividade, porque eu sou muito afetiva. Essa coisa de criar laços, de carinho,

7 Professor do ensino fundamental do $2 .^{\circ}$ segmento (6. ${ }^{\circ}$ ao $9 .^{\circ}$ ano de escolaridade). 
de conversa, de dar atenção é minha característica. Então eu utilizo isso a meu favor.

Eliane: Para se aproximar do professor a gente até conversa com relação às aplicaçóes de provas, das dificuldades que eles têm nessas provas, das formas de avaliação. A gente conversa sobre provas orais, outros instrumentos que facilitem a prova, até mesmo uma adaptação dessa prova. Então, é muito mais complicado lidar com o PI quando você fala de adaptação, do que com o PII ${ }^{8}$. Eles já estão mais abertos a isso. O PI você encontra muita resistência.

Eliane: Muitas vezes, o professor sente que você está tentando mexer com aquilo que ele já preparou. Então, às vezes, ele fala 'Ah, eu vou facilitar muito para esse aluno' e não entende que é uma questão da deficiência dele que pede que seja mexido.

Alguns educadores da turma regular demonstram dificuldade em aceitar o aluno com deficiência em sua sala de aula. Não se sentem responsáveis pela aprendizagem e desenvolvimento desse estudante. $\mathrm{O}$ Atendimento Educacional Especializado precisa realizar um trabalho intenso de aceitação dessa criança ou adolescente por parte do professor. Quando isso acontece, o trabalho do AEE junto a esse profissional deve ser pautado na paciência e na flexibilidade, para que esse empecilho não atrapalhe o processo de inclusão do aluno.

Mariana: Isso depende muito de professor para professor. Tem professor que é mais resistente. Já teve professor que eu tive que estimular mais a aceitação da inclusão do aluno, porque, por exemplo, eu orientava e ele dizia que não estava conseguindo fazer. Aí eu montei um caderno para ela e o professor disse que ela não fazia nada. Aí eu falei 'Ué, mas ela não está usando o caderno?'. Aí ele me disse que ela não tirava o caderno da mochila. Então, a gente lida com a ansiedade do professor, porque se eu chegar com força vai ser uma relação que vai ficar cada vez mais difícil. Então, tem que ter um pouco de

8 Professor do ensino fundamental do $1 .^{\circ}$ segmento (1. ${ }^{\circ}$ ao $5 .^{\circ}$ ano de escolaridade). 
tolerância e falar 'Não, mas olha, se você puder, pede para ela tirar o caderno da mochila'. A menina além de ser DI tinha uma questão familiar bem grave sabe. Pai alcóolatra, a menina não dormia à noite por causa das brigas. Então ela chegava na escola sonolenta.

Outro fator que dificulta a relação dos professores da turma regular e do atendimento educacional especializado é a rotatividade de professores dentro da unidade escolar. Muitos não possuem a formação adequada para trabalhar na perspectiva da educação inclusiva, o que bloqueia o processo de aprendizagem dos alunos público-alvo da educação especial. Diante disso, o AEE é visto como o "salvador da pátria" e precisa desenvolver estratégias de atendimento tanto para esses alunos como para os professores. É um trabalho árduo que é afetado pela ausência de uma Sala de Recursos Multifuncionais em cada escola.

Anete: Essa coisa da visita no contra turno sem encontrar os professores é muito complicada. O meu trabalho flui muito melhor hoje enquanto sala de recursos dos alunos de dentro da escola $\mathrm{B}$ do que quando eu era da sala de recursos da escola $C$ e atendia a escola $B$, porque eu vinha de 15 em 15 dias, de mês em mês, o que desse eu vinha para visitar. Você não cria laços, você não cria amizade, você não tem o dia a dia.

Se, por um lado, ele é considerado a pessoa que é capaz de resolver qualquer coisa, por outro, é tratado pela gestão como um verdadeiro estranho, um visitante que vai até a sua unidade escolar, presta um serviço e depois vai embora. Não se percebe um esforço por parte da equipe gestora para inserir o AEE no planejamento, no dia a dia da escola. Percebe-se, com essa postura, uma total ausência de um trabalho pedagógico voltado para a inclusão, além de uma completa desvalorização do profissional.

Clotilde: E, em relação à direção, se você chegar na secretaria e falar assim 'Clotilde está aí hoje?', elas vão dizer 'Clotilde? Eu não sei te dizer'.

A análise dos dados também mostrou que existem escolas nas quais os professores do AEE conseguem estabelecer uma relação de colaboração, mesmo que parcial, com os docentes da turma regular. Alguns elementos 
facilitam esse vínculo: o atendimento e o suporte dado aos regentes da turma comum satisfazem as suas necessidades pedagógicas; a comunidade escolar compreende todas as singularidades do trabalho do AEE; a predisposição de alguns professores para o trabalho colaborativo; os professores de todas as turmas conhecem as necessidades e o trabalho desenvolvido pelo AEE junto aos estudantes; o fato de as turmas de primeiro segmento serem atendidas por um único educador; equilíbrio, resignação e perseverança por parte do AEE no trato com os demais profissionais; o fato de o AEE também atuar na turma regular em outro horário; o apoio da direção; e a participação do AEE na maioria das reuniões pedagógicas.

A professora de uma unidade escolar revelou que os docentes da turma comum sentem-se amparados com relação ao atendimento que é dado aos alunos e ao suporte que é oferecido a eles pelo AEE. A compreensão do papel desse profissional por todos os envolvidos no processo educacional, mais especificamente pelo professor que está atuando junto ao aluno que apresenta deficiência, respalda o trabalho desse regente e o deixa mais seguro e à vontade para buscar novas possibilidades de ajudar essa criança ou adolescente.

Alguns professores possuem uma predisposição, uma flexibilidade para o trabalho colaborativo. Eles interagem com o outro e criam uma ajuda mútua, bilateral, pois estão engajados em um processo conjunto de tomada de decisão, trabalhando em direção a um objetivo comum: o aprendizado e o desenvolvimento dos alunos com necessidades educacionais especiais. Compartilham metas, responsabilidades e recursos. Geralmente, são educadores novos na escola e na profissão. Diante desse cenário, os resultados não demoram muito a aparecer.

Clotilde: Eu tive uma colega ano passado que realmente trabalhou comigo colaborativamente. Nós pegamos uma menina que veio da Colômbia que não falava nada em Português, que não entendia nada. Venezuela, desculpe! Nós tivemos que alfabetizá-la em Português para poder trabalhar. E aí só para você ter uma ideia do que foi trabalhar colaborativamente, nós tínhamos um caderno só. As atividades que eu fazia colava no caderno. As atividades que ela produzia, a partir das orientações que eu dava de adaptação, ela colava no caderno. A mãe dela ficou radiante porque a menina ficou aqui na escola oito meses e ela saiu daqui, não lendo, mas sabendo as famílias silábicas. 
Mariana: Atualmente eu consigo. Teve um grupo aqui que era um pouco mais resistente, mas o grupo atual é um grupo de parceria. A gente consegue fazer uma parceria.

A professora Valéria contou que um aspecto que facilita a sua interação com os demais docentes da escola é o fato de conhecerem as especificidades de todos os alunos atendidos na Sala de Recursos Multifuncionais, pois as conversas que acontecem entre eles são coletivas, e não ficam centralizadas somente no professor de determinado aluno. Nesse panorama, o estudante é visto como da escola, e não como exclusividade do educador que o atende na turma regular. Um outro cenário vivenciado, agora, pela professora Eliane também auxilia na construção de um diálogo colaborativo: o fato de os professores atuarem em turmas de primeiro segmento, onde estão todos os dias, na instituição escolar, em contato diário com o aluno, o que não ocorre com o regente de segundo segmento, que frequenta a escola somente alguns dias da semana. Essa proximidade entre ele e o estudante acaba se perdendo.

Valéria: Todo mundo conhece todas as crianças aqui da escola, porque a gente conversa muito sobre cada criança da escola, independente daquele professor. Não fico centralizada naquele professor. Eu acho isso importante.

Eliane: Então, nas turmas menores a gente tem apoio dos professores, até porque tem essa proximidade do aluno com o professor. Nas turmas maiores são vários professores e esse contato diminui. Então, nem todos os professores a gente consegue entrar em contato, porque quando a gente vai visitar, geralmente, é aquele professor do dia e as conversas ficam mais com aquele professor. E assim essa proximidade acontece mais com os alunos em que a gente encontra o PII. O PI é sempre um pouco mais difícil de lidar também.

Os dados da entrevista mostraram que, quando a professora da Sala de Recursos Multifuncionais também atua na sala de ensino regular, há uma compreensão maior com relação aos medos e às dificuldades enfrentadas pelo docente da classe comum, o que facilita a construção de relaçôes colaborativas. 


\begin{abstract}
Alana: A relação é muito boa, até porque eu também sou professora de sala comum. Então, eu entendo muito bem os questionamentos do professor de sala comum. Há três anos eu não tenho alunos incluídos pelo fato de eu estar sempre com as maiores turmas do terceiro ao quinto ano, mas eu já trabalhei muito com crianças incluídas. Eu sei o que os colegas passam. Então, essa ponte de você também saber o que o outro lado está passando é legal.
\end{abstract}

Como pudemos perceber, os dados da entrevista mostraram que existem muitos fatores que dificultam a relação do professor da turma comum com o professor da Sala de Recursos Multifuncionais. Contudo, encontramos também várias realidades que expressam possibilidades reais de mudança em favor de uma educação que valorize a aprendizagem e o desenvolvimento de todos os alunos na classe comum. Para ajudar nesse processo de mudança de posturas, valores e práticas, é necessário investir na formação continuada desses professores. Formação esta que já vem sendo oferecida desde o ano de 2013 pela Oficina Vivencial, juntamente com as professoras da UERJ, aos docentes entrevistados.

As informações que serão apresentadas neste momento fazem parte da avaliação que as entrevistadas fizeram do curso de que participaram no período de 2013 a 2016. O grupo de professores que iniciou o curso de formação no primeiro ano da pesquisa não permaneceu junto até o final do projeto. Os participantes que entraram depois sentiram, inicialmente, certa dificuldade para compreender a proposta de trabalho. Houve uma perda no processo de construção de conhecimentos deles. Contudo, com o passar do tempo e dos encontros, os objetivos e as estratégias ficaram mais claras.

Valéria: Eu me senti muito perdida. Primeiro que eu não entendia muito
bem, eu não conseguia. Quando eu entrei, na verdade, eu não conhecia mui-
to a proposta do trabalho. Aos pouquinhos eu fui conseguindo entender e tal.
É difícil você entrar num trabalho que já está sendo desenvolvido desde 2013 .
Então, assim, é meio complicado. Agora eu estou me sentindo mais segura, já
estou entendendo qual é a proposta, mas no início foi bem difícil conseguir
entrar mesmo e conseguir caminhar junto.

As professoras que participaram dos quatro anos de formação acharam que o curso contribuiu muito para a sua prática pedagógica e para mudanças 
de posturas em relação ao trabalho desenvolvido nas Salas de Recursos Multifuncionais. Os encontros serviram para enriquecer as atividades desenvolvidas junto aos alunos com deficiência e ampliou a visão para a busca de novas estratégias. A sensação de que nada que estava fazendo era correto foi substituída pelo sentimento de fortalecimento diante das vivências relatadas pelas outras regentes. Os momentos de troca de experiências entre os docentes e os formadores foi um dos pontos-chave da formação, pois elas não tinham muita noção do que era comunicação alternativa, e esses momentos favoreceram o esclarecimento das dificuldades vividas no dia a dia dos atendimentos.

\begin{abstract}
Mariana: Assim, eu achei importante e foi uma coisa que foi se estendendo. Ia ser um ano, depois virou dois, depois três anos. Então, foi tendo movimento. Não sei se já vou começar a responder as outras perguntas sem querer. Foi legal também ver aquela coisa do espelhamento. Às vezes você passa uma situação na sua escola e aí você sente que tem que ter paciência e muita tolerância. Que não pode bater de frente e tal e, às vezes, você se sente sozinha.
\end{abstract}

Karla: Eu achei ótimo, porque eu acho que tudo que vem enriquecer o nosso trabalho, ampliar a nossa visão é sempre bem-vindo. O objetivo da sala de recursos inicial, achei interessantíssimo. Eu acho que é necessário as professoras de sala de recurso estarem sempre trocando.

Eliane: Quando eu comecei, tinha aquela visão da comunicação alternativa. Era como se eu fosse uma criança dando os primeiros passos. Mas a gente vê os colegas comentando a respeito de como é o lidar delas nas salas de recursos com as crianças que tem recebido. A gente vê que o trabalho é igual, que a gente tem também as nossas dificuldades. A gente vê que uma palavra de um colega, muitas vezes, vem contribuir com o nosso trabalho.

As palestras ofertadas aos professores foram muito interessantes e ministradas por profissionais que tinham bastante experiência de vida profissional e acadêmica para transmitir. Em um primeiro momento, alguns professores não possuíam alunos com necessidade de comunicação alternativa, mas esse fato não tirou o brilho e a importância dos conhecimentos trabalhados 
pelos palestrantes. A forma como o conteúdo das aulas foi trabalhado instigou a busca por novos conhecimentos.

Joana: Eu gostei bastante, porque a gente teve muitas palestras bacanas com pessoas bacanas que trouxeram muita bagagem para a gente de informação que a gente não tinha.

Anete: De uma certa forma, acho que foi muito proveitosa. Muita coisa que eu queria aprender ainda não sei, mas, pelo menos eu já sei que aquilo existe com certeza. Então, cabe a mim agora buscar um conhecimento maior. Eu fico muito contente quando eu vou a uma palestra e eu saio dali com um pouco de interrogação na cabeça. Isso para mim é o que vale.

Clotilde: $\mathrm{O}$ início, naquela parte mais teórica, onde os convidados foram para se apresentar foi um embasamento teórico que você acha que poderia procurar na internet. Mas não, porque é diferente você procurar na internet e ler e ter o profissional falando com você. Então, eu achei que foi extremamente válido.

Um dos pontos de maior expressão do curso de formação foi o fato de os formadores serem professores ainda atuantes na área da educação especial. Nesse caso, teoria e prática caminham juntas, uma complementando e respaldando a outra. O conteúdo que está sendo trabalhado ganha credibilidade e, quando isso ocorre, as pessoas se interessam mais, pois veem significado no que estão estudando. A atividade de autoscopia, na qual as professoras filmavam suas atividades e depois assistiam e avaliavam seus procedimentos, foi um dos instrumentos que ajudou a dar sentido, relevância e uma orientação para as experiências vividas diariamente nas salas de recursos.

Anete: Eu acredito muito no trabalho de formação em que o professor seja professor ainda atuante. [...] Eu acho que esse professor está certo. Ele tem que continuar atendendo, não pode sair do atendimento porque ele passa a falar de uma teoria, no meu entender. Ele não passa mais a viver aquela prática. E quando a gente deixa de praticar, a gente perde muito a referência. Eu 
penso assim. Então, eu acho que a formação feita com quem está ali no campo com você trabalhando, trocando, sentindo na pele as mesmas dificuldades que o outro sente, é fantástico. Eu acho que isso ajuda a aumentar muito a chance de dar certo.

Anete: Foi muito interessante a questão de se ver filmar, de ver a sua filmagem. Isso é uma coisa que para mim trouxe muita luz mesmo. Às vezes eu queria que o aluno fizesse aquilo daquele jeito. Se eu fosse mais flexível, ele faria. Mas na hora você não percebe, você está tão envolvido, que não percebe.

Com relação aos procedimentos de ensino empregados pelos professores/palestrantes, os dados da pesquisa mostraram que o modo como eles se organizaram para atingir os objetivos de estudo foi muito adequado e relevante, pois priorizaram a prática, o que possibilitou a troca de experiências, o diálogo e a construção de novas estratégias de ensino e aprendizagem.

$\mathrm{O}$ curso de formação oferecido pela Oficina Vivencial, em conjunto com as professoras da UERJ, foi um grande sucesso, teve grande relevância social e acadêmica. Durante esses quatro anos de formação, detectamos na fala dos entrevistados vários pontos fortes: amadurecimento dos participantes; oportunidade de participar de congressos na UERJ; exemplos práticos trazidos pelos palestrantes; compartilhamento das experiências com a comunidade escolar; conteúdo funcional; atividades de estudo de caso; utilização de tecnologia de ponta; implementação das Salas Abertas e os laços que foram criados com os professores de outras escolas. Tivemos, também, alguns pontos que necessitam de um olhar mais atencioso por conta de terem sido citados como pontos fracos na formação. São eles: conversas paralelas durante os encontros, o que atrapalha o desenvolvimento do trabalho; pouco tempo para o desenvolvimento das atividades das Salas Abertas; deslocamento da escola até o local de formação; encontros muito distantes um do outro; datas dos cursos que coincidiam com a semana de conselho de classe ou com a semana de prova; aplicativos difíceis de serem manejados; poucas intervenções teóricas na apreciação dos vídeos; pouco tempo para organizar os encontros das Salas Abertas; e formaçóes com temas voltados somente para o público infantil. 
Esse trabalho provocou impactos nas práticas pedagógicas dos professores junto aos alunos que são atendidos nas Salas de Recursos Multifuncionais, no sentido das estratégias, da postura, da seriedade e da autoestima. Percebe-se uma diferença entre as práticas pedagógicas e as posturas dos professores antes e depois da realização do curso de formação. Ele foi decisivo, um marco na vida profissional de muitos educadores. Possibilitou uma postura mais segura diante dos atendimentos que são dados aos responsáveis pelos alunos e aos profissionais de saúde que atendem os estudantes. $\mathrm{O}$ atendimento realizado pelo AEE teve uma melhora na qualidade, pois passou a ter um olhar diferenciado para a comunicação alternativa, assim como para as experiências vividas e ouvidas e para os materiais utilizados. Esse curso deu voz e vez aos professores carentes de uma formação que estivesse de acordo com suas necessidades, e também aos alunos, que sentiam a falta de práticas pedagógicas que os auxiliassem a aprender, a desenvolver-se socialmente e emocionalmente e a interagir com o mundo.

A continuidade do curso de formação é uma possibilidade, já que ele foi de extrema relevância e significação para professores, alunos e comunidade. Algumas sugestōes, fornecidas pelos participantes no momento da entrevista, dão algumas recomendaçôes que merecem destaque, a saber: continuidade, nas formações, do modelo que já vem sendo praticado; implementação das Salas Abertas em toda a rede municipal de ensino do Rio de Janeiro; revisão das excessivas atribuiçóes dos professores das Salas de Recursos Multifuncionais; reavaliação da quantidade de alunos que são atendidos pelo AEE; mais tempo para planejar e confeccionar o material necessário para o trabalho; que a Sala de Recursos Multifuncionais de Referência torne-se um espaço de formação e de troca de experiências em cada coordenadoria regional de educação; continuação do processo de autoscopia e de estudo de caso; ampliação dos espaços de troca de experiências; formações ministradas por professores que atuam nas SRMs e priorização de temas diversificados relacionados aos alunos com deficiência.

Pode-se afirmar que a parceria entre a Oficina Vivencial e a Universidade do Estado do Rio de Janeiro, no curso de formação continuada oferecido aos professores de Salas de Recursos Multifuncionais, alcançou os objetivos propostos, pois ampliou a compreensão de questôes políticas e educacionais que visam a garantir a educação inclusiva. $\mathrm{O}$ trabalho com os professores das Salas de Recursos Multifuncionais fomentou questionamentos e posiciona- 
mentos em relação à formação do docente e também às diferentes práticas pedagógicas e aos lugares em que elas acontecem, tencionando assegurar o direito de todas as pessoas à educação escolar de qualidade. As reflexões e os debates sobre o contexto social, a escola e a atuação do professor, tanto da classe comum quanto da Sala de Recursos Multifuncionais, indubitavelmente encontrarão repercussão naqueles que desejam e que se dedicam a construir uma sociedade solidária, em que os direitos humanos sejam promovidos e respeitados. 